\title{
A review of the role of school-related factors in the promotion of student social and emotional wellbeing at post-primary level
}

\section{David Byrne , Aiden Carthy \& Sinead McGilloway}

To cite this article: David Byrne , Aiden Carthy \& Sinead McGilloway (2020) A review of the role of school-related factors in the promotion of student social and emotional wellbeing at post-primary level, Irish Educational Studies, 39:4, 439-455, DOI: 10.1080/03323315.2019.1697949

To link to this article: https://doi.org/10.1080/03323315.2019.1697949

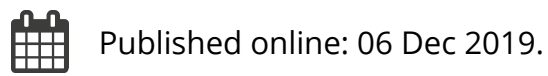

Submit your article to this journal ¿

Џll Article views: 552

Q View related articles ¿

View Crossmark data ¿ 


\title{
A review of the role of school-related factors in the promotion of student social and emotional wellbeing at post-primary level
}

\author{
David Byrne (D) ${ }^{\mathrm{a} *}$, Aiden Carthy (D) ${ }^{\mathrm{a}}$ and Sinead McGilloway (D) ${ }^{\mathrm{b}}$ \\ ${ }^{a}$ TU Dublin - Blanchardstown Campus, Department of Humanities, Dublin, Ireland; ${ }^{b}$ Department \\ of Psychology and Social Sciences, Maynooth University, Maynooth, Ireland
}

(Received 22 September 2018; accepted 17 October 2019)

In 2017, the National Council for Curriculum and Assessment (NCCA) in the Republic of Ireland introduced a universal social and emotional learning (SEL) intervention in the form of the NCCA wellbeing guidelines. These guidelines are aimed at facilitating the promotion of student wellbeing during the first three years of post-primary education. This paper will provide an overview of the NCCA wellbeing guidelines, while also establishing the educational context within which these guidelines have become necessary. While the introduction of these guidelines is arguably timely, little is known of the attitudes and perspectives that are held by the principal stakeholders, namely the educators, regarding these guidelines and the promotion of student wellbeing in general. This constitutes a significant gap in knowledge as the success (or otherwise) of the new wellbeing guidelines in Ireland may be in some way contingent upon teachers' attitudes toward both the guidelines themselves, and their ability to deliver them. It will be proposed that research, which is currently being conducted, is necessary to further understand educators' perspectives in this area in order to secure 'whole-school' implementation of the wellbeing guidelines and curricula.

Keywords: post-primary; education; social/emotional wellbeing; student; educators

\section{Introduction}

The benefits of programmes and interventions designed to promote social and emotional learning (SEL) in educational settings have been widely documented (Dowling and Barry 2017; Greenberg et al. 2017). These are typically delivered at three levels. 'Universal' interventions are designed to be used among the general student population to reduce or prevent social, emotional, and behavioural issues that are predicated by common risk factors such as stress or anxiety. This type of intervention tends not to focus on addressing individual risk factors, such as ethnicity or socio-economic background, but are more generic in their emphasis. For example, 'UPRIGHT' is an EU funded universal intervention that aims to help facilitate a general culture of mental wellbeing promotion in schools (Uprightproject.eu 2018).

'Selective' interventions target students who present with one or more specific risk factors and may therefore be at greater risk of negative outcomes. These interventions are more conceptually precise and focused than universal interventions.

\footnotetext{
*Corresponding author. Email: david.byrne@mytudublin.ie 
For example, the 'Preventure' programme in the Netherlands targets students with specific personality profiles who may be at risk of substance abuse (Lammers et al. 2017).

Finally, 'indicated' interventions target individuals who are demonstrating early signs of social, emotional, or behavioural difficulties and who are therefore considered to be high risk when compared to their peers. An example of this type of intervention would be the 'Interpersonal Psychotherapy-Adolescent Skills Training' programme (IP-AST) which is a school-based preventive mental health programme targeted at young people with depressive symptoms in the United States (Young, Mufson, and Davies 2006).

The first of these intervention types will be the primary focus of this paper. According to Greenberg et al. (2017), school-based universal interventions commonly focus on three areas; improving school structure (e.g. school policies); supporting teachers' pedagogy and instructional quality; and offering SEL curricula that promote knowledge and skills among all students. With this in mind, in 2017, the National Council for Curriculum and Assessment in Ireland (NCCA) published a new universal intervention in the form of the NCCA wellbeing guidelines. These guidelines are designed to supplement current school policies and curricula in enabling students to develop a wide range of cognitive, affective, and behavioural skills to help promote their social and emotional wellbeing. Importantly, the guidelines afford equal focus to the entire student-body rather than those who may in some way be disadvantaged by virtue of, amongst other things, socioeconomic background, ethnicity, or gender. The guidelines stipulate that, as of September 2017, all post-primary schools in Ireland are required to allocate 300 hours over the three-year junior-cycle to providing instruction in the promotion of the social and emotional wellbeing of their students, increasing to 400 hours by 2020 .

The aims of this paper are to: (1) identify and discuss a number of factors that have been identified in the international literature as influencing the wellbeing of postprimary students and are specific to the school setting; (2) describe the NCCA wellbeing guidelines and outline how they may be implemented to help promote student wellbeing, and; (3) identify current gaps in knowledge in this field and how they may be addressed.

\section{School-related factors influencing student wellbeing}

The Department of Education and Skills in Ireland (DES) (2013) identified several broad protective factors that are considered to be conducive to the development of students' social and emotional wellbeing. These include: the provision of a positive school climate; maintenance of a sense of (student) connectedness with the school; positive inter-student and student/teacher relationships; fostering expectations of high achievement; participation in extra-curricular activities, and; the provision of support and professional development for teachers. The implications of these factors with regard to students' social and emotional wellbeing will be discussed in the following section. However, it should be noted that the list of factors discussed in this paper is not exhaustive. Rather, the purpose of this section is to briefly highlight some of the more salient factors which have been consistently found to influence students' social and emotional wellbeing. 


\section{School infrastructure}

Research conducted in Belgium (Engels et al. 2004) attempted to identify a relationship between students' social and emotional wellbeing and school infrastructure. These authors concluded that school infrastructure is a significant factor with regard to students' social and emotional wellbeing, stating that 'it goes without saying that a pleasant environment and involvement in its enhancement is conducive to a positive atmosphere at school' $(2004,138)$. However, an examination of the findings of this study showed that mean scores for students' perceptions of the importance to wellbeing of infrastructure and facilities were the lowest of all considered variables. Thus, it would appear that school infrastructure, whilst important, may be less influential than other factors, and that the relationship between school infrastructure and student wellbeing may well be mediated by school climate.

Further, more recent, research also conducted in Belgium (Cuyvers et al. 2010) found that good/poor infrastructure was not highly predictive of measures of wellbeing, and that levels of student wellbeing can be significantly influenced by other factors. For example, these authors found that when schools were capable of dealing with problems, students were well behaved, and students had regular contact with their friends, the potential negative influence of less well-developed infrastructure could be mitigated to the point where measures of wellbeing can reflect those seen in schools with well-developed infrastructure. It could therefore be suggested that, while school infrastructure may influence levels of student wellbeing, this may be largely mediated by aspects of school climate such as, peer behaviour, peer relations, and teacher support. Indeed, this argument is supported by research conducted in Australia that emphasised the importance of aspects of school climate, such as academic support, academic satisfaction, school satisfaction, positive student/teacher relationships, school connectedness, and order and discipline. These aspects of the school climate are broadly representative of academic climate and inclusion/interpersonal relationships (Zullig, Huebner, and Patton 2010) and will be discussed in more detail below.

\section{School climate}

A number of studies have indicated that assessments and examinations can be a source of considerable stress and anxiety for post-primary students (Huan et al. 2008; Putwain 2009). In Ireland, it has been observed that a focus upon exam preparation typically increases as state examinations approach, with the use of active teaching methodologies (which students find most engaging) becoming more infrequent (Smyth et al. 2007). The emphasis placed upon academic achievement can contribute to a stressful academic climate which, in turn, has been demonstrated to negatively impact students' wellbeing and academic performance (Banks and Smyth 2015). Aspects of academic climate, such as the organisation of student learning and dayto-day classroom processes, have also been reported to influence student achievement over and beyond factors such as social background and prior ability (Smyth et al. 2007). In addition, Banks and Smyth (2015) found that students' self-efficacy can be greatly influenced by their perceptions of the support structures inherent within the academic climate of, and by a sense of connectedness to, the school.

School connectedness describes the quality of social relationships within the school, and the extent to which students feel like they belong at, and are cared 
for by, the school. A sense of school connectedness is positively associated with academic achievement, peer and teacher relationships, and emotional wellbeing (Waters, Cross, and Shaw 2010). Conversely, the absence of a sense of school connectedness can be indicative of poor student/peer and student/teacher relationships, poor class management (on the part of the teacher), and social isolation. This can result in a range of negative cognitive and affective outcomes such as anxiety, reduced self-esteem, and lower levels of psychological adjustment (Way, Reddy, and Rhodes 2007; Lester and Cross 2015). O'Brien (2008) argued that the degree of stress experienced due to an over-bearing academic climate could be mitigated by a healthy social climate. In this respect, O'Brien found that Irish post-primary students prioritised having at least one close friend, and the absence of bullying, as essential to their subjective wellbeing. More positive experiences of postprimary education in an Irish context were found among students with larger friendship networks (Smyth 2017). Furthermore, when friendships formed in primary education were sustained into post-primary education, Irish students were found to be more resilient against the onset of negative affect, and were more insulated against the potential for being bullied in the first year of post-primary education (O'Brien 2008).

\section{Studentlteacher relationships}

One of the most prominent and recurring themes in the literature with regard to school climate and student wellbeing is the relationship between students and their teachers (Spilt, Koomen, and Thijs 2011; INTO 2012; Smyth 2015, 2017). The student/teacher relationship has been found to account for almost $30 \%$ of the success of students at school (Hattie 2003). A study of Irish, English and American post-primary teachers found that the success of a teacher (in terms of engendering positive social, emotional, and academic outcomes for students) was strongly influenced by their ability to relate the curriculum to the every-day lives of their students (Killeavy, Collinson, and Stephenson 2003). This, the authors argued, was predicated upon teachers' deep understanding and knowledge of their students. It should be noted that there is a lack of knowledge in an Irish context regarding this aspect of the student/teacher relationship. However, several international studies do suggest that a significant proportion of a teachers' skill-set is non-academic, encompassing the ability to cultivate mutually beneficial interpersonal relationships (Telli, Den Brok, and Cakiroglu 2007; Cadima, Leal, and Burchinal 2010).

Research has also consistently identified that building positive relationships with students is one of the most important sources of enjoyment and fulfilment in teachers' careers (Hargreaves 2000; Spilt, Koomen, and Thijs 2011). It has further been suggested that relationships with students may reciprocally influence teachers' professional and personal self-views. Teachers may engage in social referencing of their students to disconfirm negative professional or relational schema. For example, teachers may engage with students to dispel potential insecurities about their teaching ability (Golby 1996; Riley 2009). Davis (2006) referred to this as 'dual relationships', whereby teachers use their relationships with students to satisfy some of their own needs. Davis suggested that this behaviour may be more likely to be exhibited by new teachers who may wish to be seen to be competent, or to be considered by students as a friend. 
Teachers have been found to highly value their relationships with students (Hargreaves 2000; Spilt, Koomen, and Thijs 2011), and such relationships have been proposed to be the optimal dynamic within which to promote the growth and fulfilment of each students' potentialities, or what is referred to as their 'self-actualisation' (Deci and Ryan 2000). It is proposed that students might best pursue self-actualisation within a 'student/teacher dialectical framework'. This framework highlights the importance of relationships in which individuals of high status or expertise attempt to motivate those of lesser status or expertise (Reeve, Deci, and Ryan 2004). Within the dialectical framework, students tend to become more highly motivated when their teachers can cultivate close interpersonal relationships, while facilitating autonomous and self-directed learning. This process is thought to be informed by three fundamental and universal psychological factors: autonomy (i.e. responsibility for selfactualisation); relatedness (i.e. support and interpersonal regard), and; competence (i.e. feeling capable of achieving desired outcomes) (Deci and Ryan 2000). Buhrmester (1990) argues that relatedness and belonging in particular become especially important as children enter adolescence, whereby the ability to maintain positive relationships is related to higher levels of sociability and self-esteem and increased selfefficacy, as well as reduced hostility, anxiousness, and depression. However, when self-determination is frustrated, motivational and regulatory processes can become maladaptive and detrimental to wellbeing.

Specific aspects of student/teacher interpersonal behaviour have been found to be among the strongest correlates of students' cognitive, emotional, and behavioural engagement (Van Uden, Ritzen, and Pieters 2013). For example, teacher 'belongingness', or the feeling of being supported and accepted by teachers, has been conceptualised as existing within a reciprocal triad along with engagement and academic autonomy. In other words, students' perceptions of academic autonomy and teacher belongingness can contribute to higher levels of academic engagement which, in turn can elicit increased support for autonomy and belongingness from teachers (Van Ryzin, Gravely, and Roseth 2009). Conversely, this relationship can become strained with the perception of excessively punitive teacher behaviour.

'Directly controlling teacher behaviours' (DCTB) are 'explicit attempts to fully and instantly change the behaviours children presently engage in or the opinions they hold' (Assor et al. 2005, 398). DCTB can present as not allowing students to work at a comfortable pace, excessive imposition of directives, and not permitting students to express opinions that differ from those of the teacher. The presence of DCTB can result in an erroneous perception of compliant and academically engaged students, as students may be too fearful of over-controlling teachers to vocalise their opinions. This, in turn, can lead to amotivation and feelings of anger and anxiety (Assor et al. 2005). For example, Smyth (2017) found that students who received excessive punitive reprimands and less positive feedback from their teachers were more likely to have negative attitudes towards school and school subjects.

\section{The influence of context upon student wellbeing}

The impact of infrastructure, climate, and connectedness upon student wellbeing can be greatly affected by the context within which a particular student may find themselves. The spectrum of contextual factors in this regard is wide and can include; the urban/rural setting; fee-paying/non-fee-paying status; single-sex vs co-educational 
practices; admissions policies, and; denomination. These factors are too numerous and too complex to be unpacked in sufficient depth in the present paper. However, the urban/rural setting is a useful exemplar of the influence of context as students of each respective setting can be presented with particular challenges with regard to infrastructure, climate, and connectedness. These challenges will now be briefly outlined.

A comprehensive study of OECD member states found that students in urban schools tend to outperform those in rural schools on most measures of wellbeing (OECD 2013). While urban/rural differences were found to be influenced by socioeconomic factors, characteristics of the urban school environment, such as autonomy and the availability of an adequate supply of teachers, were also found to be important factors. With regard to the aforementioned argument of student/teacher relationships, rural schools may be perceived to present with one distinct advantage in that schools and classes tend to be significantly smaller in rural settings (RuralSettlementIreland.com 2017) despite the growth, in the last 20 years, of larger schools in rural areas.

Smaller schools and classes may be beneficial with regard to academic performance, the development of reciprocal student/teacher relationships, and the promotion of a generally positive school climate (Darmody, Smyth, and Doherty 2010; Zahorik et al. 2012). However, smaller classes may also lead to a perception among students that they are being more closely monitored, thereby leading to a potential for student disengagement (Smyth 2015). Recent research conducted in Ireland found that students in rural DEIS ${ }^{1}$ schools, when compared to their counterparts in urban areas, were less likely to enjoy school, to like their teachers, and to take pride in their school work, while they also demonstrated lower levels of self-efficacy in terms of their aspirations for attaining third level education (Weir, Errity, and McAvinue 2015).

Research has also identified significantly lower levels of peer interaction among rural students in DEIS schools (Weir, Errity, and McAvinue 2015). Conversely, the same authors suggest that when young peoples' friends are not within easy access, the reduced time spent socialising with peers can lead to rural students developing deeper and more meaningful relationships with their parents. Indeed, approximately one third of teachers in rural schools rated home support as 'very good' compared to one quarter of their urban counterparts.

Research has consistently highlighted the importance of parental involvement with regard to both academic achievement and the promotion of student wellbeing (O’Brien 2008; Van Uden, Ritzen, and Pieters 2013; OECD 2017). However, it has been suggested that higher levels of academic achievement on the part of parents (particularly the attainment of a third level qualification) could increase academic anxiety in students as they can feel more pressure to perform in school (Smyth 2015). Considering that Weir, Errity, and McAvinue (2015) found parents in rural DEIS settings to be more highly educated than their urban counterparts, the cause of the discrepancy in wellbeing between students in an urban and rural setting could be partially attributed to the perception of increased academic stressors on the part of the rural students. The increased proximity to both teachers and parents, which would otherwise be beneficial to academic outcomes and emotional wellbeing, may result in increased levels of academic anxiety amongst rural students.

Academic anxiety (amongst other things) may be alleviated, at least in part, through participation in extra-curricular and pro-social activities (Fredricks and Eccles 2008). While the rural context can present some difficulties in terms of 
accessing such activities, the research conducted by Weir, Errity, and McAvinue (2015) regarding urban and rural DEIS schools found that rural-based students are more likely to engage in structured activities such as sport, with urban students tending to engage in unstructured activities such as attendance at youth clubs and recreational centres. The former has been shown to predict a greater sense of belonging and higher levels of academic aspiration (Darling, Caldwell, and Smith 2005; Fredricks and Eccles 2008), while the latter can predict problematic behaviour (Hoeben and Weerman 2016), particularly among those from disadvantaged backgrounds (Booth, Farrell, and Varano 2008). The sometimes-remote nature of the Irish countryside can often present difficulties with regard to availability of, and accessibility to, sports facilities. As a result, rural schools can frequently function as community hubs (Fahey, Delaney, and Gannon 2005). The inconvenience of inaccessibility may then inadvertently benefit rural students as, for example, the available extra-curricular activities are more likely to be structured in nature.

\section{A summary position on student wellbeing}

The influences upon student wellbeing are numerous. An adaptive school climate has been found to be one of the most salient factors in promoting the development of students' social and emotional wellbeing. However, it has been demonstrated that the academic climate in Irish schools may contribute to the onset of academic anxiety among students, particularly as students prepare for state examinations. Nurturing students' self-efficacy can insulate against this anxiety, while instilling a positive social climate and promoting student connectedness can have reciprocal benefits for both students and teachers. School climate can be significantly influenced by context, as demonstrated through the example of the urban/rural setting, with factors such as academic pressure and student/teacher relationships tending to vary across these settings. In light of the many challenges students face in this regard, a number of policies and directives have recently been put in place to attend to the overall wellbeing of junior-cycle students.

\section{Responding to the wellbeing needs of junior-cycle students in Ireland}

Over the last decade, there has been a noticeable increase in the movement towards addressing the issue of student wellbeing in Irish schools. A number of policy documents have been released that establish a framework within which schools are afforded a large degree of autonomy in developing and implementing policies and practices to realise the maximum potential of their students' wellbeing (see, for example 'Wellbeing policy statement and framework for practice 2018-2023' [Department of Education and Skills 2018], 'A framework for improved health and wellbeing, 2013-2025' [Department of Health 2013], and 'Better Outcomes, Brighter Futures: The national policy framework for children and young people 2014-2020' [Department of Children and Youth Affairs 2014]). In 2017, the NCCA wellbeing guidelines were introduced to complement the integration of these policies and frameworks, and to further assist schools to develop their students' social and emotional wellbeing.

The stated aim of these guidelines is to 'support schools in planning and developing a coherent wellbeing program that builds on the understandings, practices and curricula for wellbeing already existing in schools' (NCCA 2017, 8). The guidelines 
challenge the perceived traditional tendency to conceptualise positive student wellbeing as the achievement of sustained positive feelings and attitudes, instead arguing that positive wellbeing should be considered 'less a state of being but more as a process of well-becoming' (NCCA 2017, 15). It is specified that wellbeing is a life long journey and that it is important to communicate to students that there will be setbacks and times of low moods, feelings, etc., as they pursue their most balanced state of wellbeing.

The NCCA guidelines state that student wellbeing should be assessed in relation to six indicators of wellbeing; being active, responsible, connected, resilient, respected, and aware (NCCA 2017, 45). It is suggested that teachers should regularly and informally monitor their students for these indicators, with emphasis placed on the importance of ongoing assessment. This is considered necessary in providing 'an overview of the knowledge, skills and attitudes that students are moving towards achieving in support of their wellbeing' (NCCA 2017, 72). It is also stated that 'the focus of wellbeing assessment is to gather evidence of what the student has learned about wellbeing, i.e. the knowledge, skills and dispositions students have gained' (NCCA 2017, 72). More formal reporting practices are proposed to be conducted intermittently, including self-report questionnaires (for both students and teachers), poster presentations, and video assignments. At the end of the third academic year (i.e. the end of the junior-cycle), schools will be provided with templates for reporting on wellbeing in accordance with the Junior Cycle Profile of Achievement (JCPA). These templates are formatted to gather information regarding students' achievements in the state-certified final examinations; Classroom-Based Assessments (CBA) in subjects and short courses, where relevant; other areas of learning, and; L2 Learning programmes (L2LP's), ${ }^{2}$ where relevant (Department of Education and Skills 2017).

While the introduction of these guidelines is arguably necessary and timely in the current education climate, there are a number of aspects regarding design, implementation, and assessment that may need attention. For example, the assessment methodology (i.e. how the guidelines propose student wellbeing should be assessed) tends to emphasise students' knowledge and understanding of the concept of wellbeing at the expense of understanding students' own subjective experiences of developing their wellbeing. The guidelines state that

assessment in wellbeing is not about teachers assessing where the student is situated on the continuum of wellbeing or the students' subjective state of wellbeing. It would be counterproductive for a teacher to make a judgement about a student's wellbeing per se.... (NCCA 2017, 72)

It could be argued here that accounting for the subjective experiences of students would help to promote a more holistic understanding of the process of 'wellbecoming'.

Furthermore, there is, as yet, no planned evaluation of the extent to which the wellbeing guidelines contribute to improving student wellbeing. Thus, while the indicators of wellbeing within the guidelines closely reflect Seligman's (2003) 'PERMA' model of wellbeing - which is a widely supported approach toward promoting student wellbeing (Kern et al. 2014; The Royal School 2019) - there is no attendant measurement of impact in this respect. For example, aspects of wellbeing may be assessed on an ongoing basis using tools such as the 'Satisfaction with Life Scale' and the 'Growth 
Mindset Scale' (e.g. to assess the extent to which students believed their mindsets to be fixed versus open to growth and experience) (Kern et al. 2014). Finally, and perhaps most pertinently, the implementation of the wellbeing guidelines would arguably benefit from the input of the educators involved in delivering the wellbeing curriculum.

\section{Educators' attitudes with regard to wellbeing curricula}

In highlighting the importance of educators in implementing interventions aimed at supporting and enhancing student social and emotional wellbeing, the NCCA guidelines aptly identify that 'wellbeing starts with the staff' (NCCA 2017, 29). It is further proposed that teachers require professional development to ensure that they build a deep conceptual understanding of wellbeing and are confident in utilising the approaches necessary to nurture student wellbeing. Positive teacher perceptions of the wellbeing programme, and an understanding of how teachers can contribute to the wellbeing of their students, are considered to be essential to the success of any wellbeing programme. Likewise, according to Barrow (1981), the teacher plays a central role in the educational process and, therefore, the impact of health education upon pupils is not only dependent upon the knowledge and skills of the teacher, but also upon their perceptions, attitudes, and personal example. However, developing a holistic understanding of educators' attitudes with regard to their role in promoting the social and emotional wellbeing of their students is an area that is somewhat under-represented in the available literature. That said, there is considerable research that focuses on particular cohorts, contexts, and variables, which may allow for tentative inferences to be made about educators' general attitudes toward promoting student wellbeing.

For example, research conducted in Cyprus indicated that the more positive teachers are about their own health, the more positive they are likely to be about health education as a part of their schools' curriculum (Fontana and Apostolidou 2002). However, subsequent research conducted by Apostolidou and Fontana (2003) suggests that teachers' attitudes towards the implementation of wellbeing interventions may not be wholly positive. Indeed, in their follow-up study, it was found that, whilst $87 \%$ of teachers welcomed the opportunity to teach health education, $61 \%$ believed the school curriculum to be overloaded and unable to accommodate health education. Furthermore, teachers largely felt inadequately trained to deliver health education, with $82 \%$ identifying the need for more in-service training in 'health matters', and $84 \%$ indicating a need for training in 'the methodology of health education'. The authors proposed that training in health education would facilitate the development of more positive attitudes toward the teaching of the subject. A similar trend was identified with regard to the implementation of a more specified healthy life-style intervention in South Africa (Hill et al. 2015). This study examined the implementation of the 'HealthKick' intervention, which aims to promote a healthy lifestyle among students, with a particular focus on student diet. Among the six participating schools, it was found that teachers' perceptions of an already heavy workload and a reluctance to participate in non-compulsory activities were the most prominent barriers to implementation. However, it was also found that an appropriate introduction to the programme and continued interaction and support for teachers were beneficial to teacher perception and programme implementation. 
A recent review of the literature which examined the implementation of a universal SEL (the MindUP programme) also found that teachers required more training with regard to delivering many aspects of SEL curricula (Maloney et al. 2016). There would appear to be a recurring theme within the literature which highlights training and workload as significant factors influencing teachers' perceptions of wellbeing curricula (Apostolidou and Fontana 2003; Hill et al. 2015; Byrne, Rietdijk, and Pickett 2018). There may also be a degree of discomfort among teachers with regard to the delivery of some aspects of the wellbeing curricula. For example, Shannon and Smith (2015) observed that teachers in Australia felt considerable discomfort when involved in the delivery of sexuality education. It was also suggested that teachers may tend to be somewhat reticent with regard to Lesbian, Gay, Bisexual, Transgendered, Queer, Inter-sex (LGBTQI) students as a result of a lack of training and a perceived ambiguity with regard to relevant school policy.

Similar to the issues of training and workload, teacher discomfort is commonly reported with regard to the requirements of attending to the social and emotional wellbeing of students (Walter, Gouze, and Lim 2006; Moor et al. 2007). For example, research conducted by Rothì, Leavey, and Best (2008) found that teachers in England expressed concern about the changing nature of their responsibilities with regard to attending to the wellbeing of their students. It was also noted that a requirement to attend to the social and emotional wellbeing of students could negatively impact job satisfaction and teachers' own psychological wellbeing. A similar sentiment was reported among Irish teachers as $71 \%$ of schools reported teacher discomfort with delivering Relationship and Sexuality Education (RSE) to be the most significant barrier to full implementation of this aspect of the curriculum. Furthermore, $82 \%$ of schools reported that the curriculum was too overcrowded to accommodate the RSE curriculum, with approximately two-thirds agreeing that the delivery of RSE adds to the perceived pressure in delivering core exam subjects (Mayock, Kitching, and Morgan 2007). A more recent study highlighted the issue of subject status with regard to the greater SPHE curriculum. It was found that, although teachers identified the benefits of SPHE (in this case, for male students), consideration for the importance of this aspect of the curriculum tended to be marginalised, with teachers tending to focus on the delivery of the core exam subjects (Doyle 2017). This may in part be attributed to a lack of understanding of the benefits, for both students and teachers, of the whole-school implementation of the SPHE curriculum (Nic Gabhainn and Barry 2013). Indeed, Moynihan, Jourdan, and Mannix McNamara (2016) make the argument that Irish educational policy needs to conceptualise the wholeschool approach more clearly.

With regard to teachers' tendency to focus on core exam subjects, the opposite would appear to be true for support staff such as guidance counsellors. A review conducted by the Institute of Guidance Counsellors (2016) found that, due to a sustained reduction in resources since the 2012 Budget, there has been an overall decrease in guidance counsellor practice hours, as well as a preference for classroom guidance at the expense of one-to-one guidance, and an increase in guidance counsellors performing a full-time teaching role. Unlike teachers, guidance counsellors have argued strongly for their need to attend to the pastoral care of their students (Hearne and Galvin 2014; Hearne, Geary, and Martin 2017). Thus, while teachers feel that their delivery of the core curriculum may be hindered by the requirement to attend to student wellbeing, guidance counsellors view the requirement to assist in the delivery of the core 
curriculum as a barrier to their delivery of pastoral care. This may prove to be problematic in terms of the whole-school approach to implementation that is advocated by the NCCA (2017).

Indeed, it may well be that guidance counsellors might be the most appropriate leaders with regard to the implementation of the wellbeing guidelines. For instance, Hearne and Galvin $(2014,236)$ argue that

if the guidance counsellors were to become more involved in the promotion and in-house training of a whole-school approach, as well as pastoral care training, it might encourage more regular teachers to engage in pastoral care activities in the school.

Thus, guidance counsellors could play a key role in helping to dispel the perception among teachers of pastoral care as burdensome, and help to secure teacher buy-in to the whole-school approach to promoting student wellbeing. However, this may prove to be challenging in view of the historical and current resource constraints experienced by guidance counselling services, particularly at a junior-cycle level (Hearne, Geary, and Martin 2017).

\section{Directions for future research}

The available literature suggests that there are a large number of factors which impact upon the social and emotional wellbeing of students in post-primary education - too many to be explored within the scope of this paper. However, school culture was highlighted here as important, with particular consideration for the student/teacher relationship and the importance of establishing a healthy student/teacher dialectical framework. The complexity inherent in maintaining this relationship was demonstrated with one example of a moderating variable, namely the urban/rural context. The number and complex nature these factors arguably supports the need to introduce wellbeing guidelines for schools (as in the case of the NCCA guidelines in Ireland). However, future research may be necessary to examine how well these guidelines function in terms of impacting positively (or not) on student wellbeing in Irish schools. Further research might also examine the attitudes and opinions of educators and incorporate these into the design and implementation of any wellbeing intervention.

The importance of positive teacher perceptions of wellbeing policies and curricula is clearly in evidence throughout the international literature. It can be seen that negative teacher perceptions of such policies and curricula may inhibit the development of a healthy student/teacher dialectical framework which, in turn, can negatively impact student wellbeing. It has also been shown that, while there may be concerns regarding training and teacher comfort in delivering wellbeing curricula, teachers tend to have largely positive views of SEL programmes and the promotion of student wellbeing. However, relatively little research has been conducted in this regard within an Irish context. With the recent implementation of the NCCA wellbeing guidelines, an ideal opportunity exists to examine the attitudes and opinions of Irish post-primary educators with regard to the strengths, weaknesses, and implementation of these new guidelines.

We are currently conducting research which will address this gap in knowledge by examining educators' attitudes towards the wellbeing guidelines and the wider wellbeing curricula. This research will: (1) explore the attitudes and opinions of educators toward the promotion of student wellbeing in Irish post-primary schools; (2) examine 
the attitudes and opinions of educators toward the recently published wellbeing guidelines; (3) identify any potential issues or barriers that educators may feel pertain to the development of student wellbeing; and (4) identify any changes to the wellbeing curriculum that educators may believe necessary to ensure the effective promotion of student wellbeing. This research will represent the first large-scale attempt to incorporate the attitudes and opinions of Irish educators into the provision of potential recommendations for refinement within the wellbeing guidelines and/or curricula, thus, contributing to the continued enhancement of best-practice with regard to the promotion of students' social and emotional wellbeing.

\section{Conclusion}

The recently introduced NCCA wellbeing guidelines (2017) aim to facilitate the development of a set of cognitive, affective, and behavioural skills in students from all socioeconomic and demographic backgrounds. It is widely noted within the literature that teachers play a significant role in the successful implementation, and effectiveness, of any SEL programme or curriculum. It follows, therefore, that the success (or otherwise) of the new wellbeing guidelines in Ireland may be in some way contingent upon teachers' attitudes toward both the guidelines themselves, and their ability to deliver them. However, little is known about the attitudes of teachers towards the wellbeing guidelines or the promotion of student wellbeing. To this end, the research that is currently underway will provide important insights into educators' attitudes toward, and opinions of, the new guidelines and the wider wellbeing curricula as well as the barriers and facilitators to successful implementation.

\section{Notes}

1. DEIS (Delivering Equality of Opportunity in Schools) is an integrated school support programme used by the Department of Education and Skills to address educational disadvantage in the Republic of Ireland. For more information see https://www.education.ie/en/ Schools-Colleges/Services/DEIS-Delivering-Equality-of-Opportunity-in-Schools-/

2. L2 Learning Programmes are designed to provide students with special educational needs (of higher functioning moderate and low functioning mild categories), with a Junior Certificate aligned to level 2 of the National Framework of Qualifications (NFQ).

\section{Notes on contributors}

David Byrne is a PhD student based at the Blanchardstown Campus of TU Dublin. David's primary areas of research interest are mental health/wellbeing, group dynamics, and gender. David's current research involves an examination of Irish post-primary educators' attitudes regarding the promotion of student social and emotional wellbeing.

Aiden Carthy directs the Research Centre for Psychology, Education and Emotional Intelligence (PEEI) which is located on the Blanchardstown Campus of Technological University Dublin. Aiden's principal areas of research interest are mental health and applied education. Specifically, Aiden's work focuses on using emotional intelligence coaching to enable educators, students and others to reach their maximum potential and on research related to student support and educational design.

Professor Sinead McGilloway is founder Director of the Centre for Mental Health and Community Research in the Department of Psychology and Social Sciences Institute at Maynooth 
University. (www.cmhcr.eu). She is a Chartered Psychologist and Chartered Scientist with the British Psychological Society (BPS) and an Associate Fellow of the BPS. Professor McGilloway has extensive experience in undertaking engaged policy- and practice-relevant research in the field of health and social care, with a particular focus on child and adult mental health and wellbeing and service evaluation. She is widely published, has won significant funding to date, and is currently leading/supervising a large number of interdisciplinary engaged research programmes and projects, including several which focus on wellbeing in schools.

\section{ORCID}

David Byrne (D) http://orcid.org/0000-0002-0587-4677

Aiden Carthy (D) http://orcid.org/0000-0002-4153-7889

Sinead McGilloway (D) http://orcid.org/0000-0003-0988-3201

\section{References}

Apostolidou, M., and D. Fontana. 2003. "Teacher Attitudes Towards Health Education in Greek-Speaking Cyprus Schools." Health Education 103 (2): 75-82. doi:10.1108/ 09654280310467690.

Assor, A., H. Kaplan, Y. Kanat-Maymon, and G. Roth. 2005. "Directly Controlling Teacher Behaviors as Predictors of Poor Motivation and Engagement in Girls and Boys: The Role of Anger and Anxiety." Learning and Instruction 15 (1): 397-413. doi:10.1016/j. learninstruc.2005.07.008.

Banks, J., and E. Smyth. 2015. "'Your Whole Life Depends on It': Academic Stress and Highstakes Testing in Ireland.” Journal of Youth Studies 18 (5): 598-616. doi:10.1080/13676261. 2014.992317.

Barrow, R. 1981. Philosophy of Schooling. London: Wheatsheaf Books.

Booth, J. A., A. Farrell, and S. P. Varano. 2008. "Social Control, Serious Delinquency, and Risky Behavior." Crime \& Delinquency 54 (3): 423-456. doi:10.1177/0011128707306121.

Buhrmester, D. 1990. "Intimacy of Friendship, Interpersonal Competence, and Adjustment During Preadolescence and Adolescence." Child Development 61 (4): 1101-1111. doi:10. 2307/1130878.

Byrne, J., W. Rietdijk, and K. Pickett. 2018. "Teachers as Health Promoters: Factors That Influence Early Career Teachers to Engage with Health and Wellbeing Education." Teaching and Teacher Education 69: 289-299. doi:10.1016/j.tate.2017.10.020.

Cadima, J., T. Leal, and M. Burchinal. 2010. "The Quality of Teacher-Student Interactions: Associations with First Graders' Academic and Behavioral Outcomes." Journal of School Psychology 48 (6): 457-482. doi:10.1016/j.jsp.2010.09.001.

Cuyvers, K., G. D. Weerd, S. Dupont, S. Mols, and C. Nuytten. 2010. "Well-being at School: Does Infrastructure Matter?" University of Antwerp. Accessed August 2, 2018. https:// www.oecd.org/edu/innovation-education/centreforeffectivelearningenvironmentscele/ 49167628.pdf.

Darling, N., L. L. Caldwell, and R. Smith. 2005. "Participation in School-based Extracurricular Activities and Adolescent Adjustment." Journal of Leisure Research 37 (1): 51-76. http:// plaza.ufl.edu/asarkees/PSY\%203220/ECsSelfEsteem/4-\%20Darling.pdf.

Darmody, M., E. Smyth, and C. Doherty. 2010. "Designing Primary Schools for the Future (16)." Economic and Social Research Institute. Accessed May 15, 2018. https://www.esri. ie/pubs/RS16.pdf.

Davis, H. 2006. "Exploring the Contexts of Relationship Quality between Middle School Students and Teachers." The Elementary School Journal 106 (3): 193-223. doi:10.1086/501483.

Deci, E. L., and R. M. Ryan. 2000. "The 'What' and 'Why' of Goal Pursuits: Human Needs and the Self-determination of Behavior." Psychological Inquiry 11 (4): 227-268. doi:10.1207/ s15327965pli1104_01.

Department of Children and Youth Affairs. 2014. "Better Outcomes, Brighter Futures: The National Policy Framework for Children \& Young People 2014-2020.” The Stationery 
Office. Accessed August 12, 2018. https://www.dcya.gov.ie/documents/cypp_framework/ BetterOutcomesBetterFutureReport.pdf.

Department of Education and Skills. 2017. "Junior Cycle Profile of Achievement (JCPA) Handbook for Schools." Department of Education and Skills. Accessed July 11, 2018. https://www.education.ie/en/Schools-Colleges/Services/Returns/Post-Primary-Online-

Database-P-POD-Project/junior-cycle-profile-of-achievement-jcpa-handbook-for-schools2017-.pdf.

Department of Education and Skills. 2018. "Wellbeing Policy Statement and Framework for Practice 2018-2023." Department of Education and Skills. Accessed March 2, 2019. https://www.education.ie/en/Publications/Policy-Reports/wellbeing-policy-statement-andframework-for-practice-2018\%E2\%80\%932023.pdf.

Department of Education and Skills, Department of Health, Health Service Executive, and National Educational Psychological Service Agency. 2013. "Well-being in Post-primary Schools: Guidelines for Mental Health Promotion and Suicide Prevention." Department of Education and Skills. Accessed March 2, 2019. https://www.education.ie/en/SchoolsColleges/Information/Resources-Guidance/Well-Being-in-Post-Primary-Schools-Guidelinesfor-Mental-Health-Promotion-and-Suicide-Prevention-2013.pdf.

Department of Health. 2013. "Healthy Ireland: A Framework for Improved Health and Wellbeing 2013-2025.” Department of Health. Accessed April 29, 2018. http://health.gov. ie/wp-content/uploads/2014/03/HealthyIrelandBrochureWA2.pdf.

Dowling, K., and M. M. Barry. 2017. "An Evaluation of the MindOut (2) Programme in Disadvantaged Post - Primary Schools: A Report on Preliminary Findings." Produced by the Health Promotion Research Centre, National University of Ireland Galway.

Doyle, E. 2017. "An Exploratory Study of the Perceived Benefits of SPHE (From a Teachers Perspective) for Junior Cycle Male Students and Its Implications for the Guidance Counselling Service." Master's thesis, University Limerick, Limerick, Rep. of Ireland. https://ulir.ul.ie/bitstream/handle/10344/6475/Doyle_2017_exploration.pdf?sequence $=6$.

Engels, N., A. Aelterman, K. Van Petegem, and A. Schepens. 2004. "Factors Which Influence the Well-being of Pupils in Flemish Secondary Schools." Educational Studies 30 (2): 127-143. doi:10.1080/0305569032000159787.

Fahey, T., L. Delaney, and B. Gannon. 2005. "School Children and Sport in Ireland." Economic and Social Research Institute. Accessed March 28, 2018. http://www.sportireland.ie/ Research/School_Children_Sport_2005_/ESRI_School_Children_.pdf.

Fontana, D., and M. Apostolidou. 2002. "A Survey of Teachers' Health Lifestyles in Cyprus." Health Education Journal 61 (1): 70-77. doi:10.1177/00178969020610010.

Fredricks, J. A., and J. S. Eccles. 2008. "Participation in Extracurricular Activities in the Middle School Years: Are There Developmental Benefits for African American and European American Youth?" Journal of Youth and Adolescence 37 (9): 1029-1043. doi:10.1007/ s10964-008-9309-4.

Golby, M. 1996. "Teachers' Emotions: an Illustrated Discussion." Cambridge Journal of Education 26 (3): 423-434. doi:10.1080/0305764960260310.

Greenberg, M. T., C. E. Domitrovich, R. P. Weissberg, and J. A. Durlak. 2017. "Social and Emotional Learning as a Public Health Approach to Education." The Future of Children 27 (1): 13-32. https://www.researchgate.net/publication/319480602.

Hargreaves, A. 2000. "Mixed Emotions: Teachers' Perceptions of Their Interactions with Students." Teaching and Teacher Education 16 (8): 811-826. doi:10.1016/s0742-051x (00)00028.

Hattie, J. 2003. "Teachers Make a Difference. What is the Research Evidence?" Paper presented at Australian Council for Educational Research, Melbourne, October.

Hearne, L., and J. Galvin. 2014. "The Role of the Regular Teacher in a Whole School Approach to Guidance Counselling in Ireland." British Journal of Guidance \& Counselling 43 (2): 229 240. doi:10.1080/03069885.2014.952622.

Hearne, L., T. Geary, and N. Martin. 2017. "Guidance Counselling as a Whole School Responsibility in the Irish Post Primary Sector." British Journal of Guidance \& Counselling 45 (2): 138-152. doi:10.1080/03069885.2016.1254725.

Hill, J., C. E. Draper, A. De Villiers, J. M. Fourie, S. Mohamed, W. Parker, and N. Steyn. 2015. "Promoting Healthy Lifestyle Behaviour Through the Life-orientation Curriculum: 
Teachers' Perceptions of the HealthKick Intervention." South African Journal of Education 35 (1): 1-9. doi:10.15700/201503070003.

Hoeben, E. M., and F. M. Weerman. 2016. "Why is Involvement in Unstructured Socializing Related to Adolescent Delinquency?” Criminology 54 (2): 242-281. doi:10.1111/1745-9125. 12105.

Huan, V. S., Y. L. See, R. P. Ang, and C. W. Har. 2008. "The Impact of Adolescent Concerns on Their Academic Stress." Educational Review 60 (2): 169-178. doi:10.1080/ 00131910801934045.

Institute of Guidance Counsellors. 2016. "National Audit of Guidance Counselling Practice in Second Level Schools \& Colleges of Further Education in Ireland 2011/12 - 2015/16 (Audit 4)." Institute of Guidance Counsellors. http://www.igc.ie/download/1/IGC $\% 20 \mathrm{FINAL} \%$ 20Audit $\% 204 \% 20$ REPORT $\% 20-\% 20$ May $\% 205-2$.pdf.

INTO. 2012. "Wellbeing in the Classroom: Discussion Document and Proceedings of the Consultative Conference on Education 2012." Dublin: Irish National Teachers Organisation.

Kern, M. L., L. E. Waters, A. Adler, and M. A. White. 2014. "A Multidimensional Approach to Measuring Well-being in Students: Application of the PERMA Framework." The Journal of Positive Psychology 10 (3): 262-271. doi:10.1080/17439760.2014.936962.

Killeavy, M., V. Collinson, and H. J. Stephenson. 2003. "Making Curriculum Relevant to the Lives of Second Level Students: Teachers' Classroom Practice." Irish Educational Studies 22 (1): 105-120. doi:10.1080/0332331030220110.

Lammers, J., F. Goossens, P. Conrod, R. Engels, R. W. Wiers, and M. Kleinjan. 2017. "Effectiveness of a Selective Alcohol Prevention Program Targeting Personality Risk Factors: Results of Interaction Analyses." Addictive Behaviors 71: 82-88. doi:10.1016/j. addbeh.2017.02.030.

Lester, L., and D. Cross. 2015. "The Relationship Between School Climate and Mental and Emotional Wellbeing Over the Transition From Primary to Secondary School." Psychology of Well-being 5 (9): 1-15. doi:10.1186/s13612-015-0037-8.

Maloney, J. E., M. S. Lawlor, K. A. Schonert-Reichl, and J. Whitehead. 2016. "A Mindfulnessbased Social and Emotional Learning Curriculum for School-aged Children: The MindUP Program." In Handbook of Mindfulness in Education. Mindfulness in Behavioral Health, edited by K. Schonert-Reichl and R. W. Roeser, 313-334. New York, NY: Springer.

Mayock, P., K. Kitching, and M. Morgan. 2007. "RSE in the Context of SPHE: An Assessment of the Challenges to Full Implementation of the Programme in Post-primary Schools." Department of Education and Science. Accessed March 22, 2018. https://www.education. ie/en/Schools-Colleges/Information/Post-Primary-School-Policies/2007-RSE-in-the-contextof-SPHE-An-Assessment-of-the-Challenges-to-Full-Implementation-of-the-Programme-inPost-Primary-Schools-Summary-Report-.pdf.

Moor, S., M. Ann, M. Hester, W. J. Elisabeth, E. Robert, W. Robert, and B. Caroline. 2007. "Improving the Recognition of Depression in Adolescence: Can We Teach the Teachers?" Journal of Adolescence 30 (1): 81-95. doi:10.1016/j.adolescence.2005.12.001.

Moynihan, S., D. Jourdan, and P. Mannix McNamara. 2016. "An Examination of Health Promoting Schools in Ireland.” Health Education 116 (1): 16-33. doi:10.1108/he-03-20140045.

NCCA. 2017. “Junior Cycle Wellbeing Guidelines.” NCCA. https://www.ncca.ie/media/2487/ wellbeingguidelines_forjunior_cycle.pdf.

Nic Gabhainn, S., and M. Barry. 2013. "The Implementation of SPHE at Post-primary School Level: A Case Study Approach.” NUI Galway. http://www.nuigalway.ie/hbsc/documents/ nuig_sphe_evaluation_full_report_english.pdf.

O'Brien, M. 2008. "Well-being and Post-primary Schooling: A Review of the Literature and Research." Dublin: National Council for Curriculum and Assessment. Accessed January 22, 2018. http://www.ncca.ie/ga/Foilseach $\% \mathrm{C} 3 \% \mathrm{~A} 1 \mathrm{n} /$ Tuarasc $\% \mathrm{C} 3 \%$ A 1 lacha/Well-being and_Post_Primary_Schooling_A_review_of_the_literature_and_research.pdf.

OECD. 2013. "Pisa in Focus (28)." Organisation for Economic Cooperation and Development. Accessed February 19, 2018. https://www.oecd.org/pisa/pisaproducts/pisainfocus/pisa\%20in $\% 20$ focus $\% 20$ n $28 \% 20 \% 28$ eng $\% 29-$ FINAL.pdf.

OECD. 2017. PISA 2015 Results (Volume III): Students' Well-being. PISA. Paris: OECD Publishing. doi:10.1787/9789264273856-en. 
Putwain, D. W. 2009. "Assessment and Examination Stress in key Stage 4." British Educational Research Journal 35: 391-411. doi:10.1080/01411920802044404.

Reeve, J., E. L. Deci, and R. M. Ryan. 2004. "Self-determination Theory: A Dialectical Framework for Understanding the Sociocultural Influences on Student Motivation." In Research on Sociocultural Influences on Motivation and Learning: Big Theories Revisited, edited by D. M. McInerney and S. Van Etten Greenwich, 3-33. Greenwich, CT: Information Age Press.

Riley, P. 2009. "An Adult Attachment Perspective on the Student-Teacher Relationship \& Classroom Management Difficulties." Teaching and Teacher Education 25 (5): 626-635. doi:10.1016/j.tate.2008.11.018.

Rothì, D. M., G. Leavey, and R. Best. 2008. "On the Front-line: Teachers as Active Observers of Pupils' Mental Health.” Teaching and Teacher Education 24 (5): 1217-1231. doi:10.1016/j. tate.2007.09.011.

The Royal School. 2019. "Well-being and Happiness - PERMA.” Accessed February 19, 2019. https://royalschool.com/curriculum/well-being-and-happiness-perma/.

RuralSettlementIreland.com. 2017. "Rural Resettlement Ireland." Accessed November 2, 2017. http://www.ruralresettlement.com/live_schools.html.

Seligman, M. E. 2003. Authentic Happiness: Using the New Positive Psychology to Realize Your Potential for Lasting Fulfilment. London: Nicholas Brealey.

Shannon, B., and S. J. Smith. 2015. "A Lot More to Learn Than Where Babies Come From': Controversy, Language and Agenda Setting in the Framing of School-based Sexuality Education Curricula in Australia." Sex Education 15 (6): 641-654. doi:10.1080/14681811. 2015.1055721.

Smyth, E. 2015. "Wellbeing and School Experiences among 9- and 13-Year-Olds: Insights from the Growing Up in Ireland Study." Accessed November 22, 2017. https://www.esri.ie/ publications/wellbeing-and-school-experiences-among-9-and-13-year-olds-insights-fromthe-growing-up-in-ireland-study/.

Smyth, E. 2017. "Off to a Good Start? Primary School Experiences and the Transition to Second-level Education (5).” ESRI. Accessed November 22, 2017. http://www.esri.ie/pubs/ BKMNEXT343.pdf.

Smyth, E., A. Dunne, M. Darmody, and S. McCoy. 2007. Gearing Up for the Exam? The Experiences of Junior Certificate Students. Dublin: Liffey Press/ESRI.

Spilt, J. L., H. M. Koomen, and J. T. Thijs. 2011. "Teacher Wellbeing: The Importance of Teacher-Student Relationships.” Educational Psychology Review 23 (4): 457-477. doi:10. 1007/s10648-011-9170-y.

Telli, S., P. Den Brok, and J. Cakiroglu. 2007. 'Students' Perceptions of Science Teachers' Interpersonal Behaviour in Secondary Schools: Development of a Turkish Version of the Questionnaire on Teacher Interaction.” Learning Environments Research 10 (2): 115-129. doi:10.1007/s10984-007-9023-2.

Uprightproject.eu. 2018. "Upright.” Accessed June 12, 2018. http://uprightproject.eu/.

Van Ryzin, M. J., A. A. Gravely, and C. J. Roseth. 2009. "Autonomy, Belongingness, and Engagement in School as Contributors to Adolescent Psychological Well-Being." Journal of Youth and Adolescence 38 (1): 1-12. doi:10.1007/s10964-007-9257-4.

Van Uden, J. M., H. Ritzen, and J. M. Pieters. 2013. "I Think I Can Engage My Students. Teachers' Perceptions of Student Engagement and Their Beliefs About Being a Teacher." Teaching and Teacher Education 32: 43-54. doi:10.1016/j.tate.2013.01.004.

Walter, H. J., K. Gouze, and K. G. Lim. 2006. "Teachers' Beliefs About Mental Health Needs in Inner City Elementary Schools." Journal of the American Academy of Child \& Adolescent Psychiatry 45 (1): 61-68. doi:10.1097/01.chi.0000187243.17824.6c.

Waters, S., D. Cross, and T. Shaw. 2010. "Does the Nature of Schools Matter? An Exploration of Selected School Ecology Factors on Adolescent Perceptions of School Connectedness." British Journal of Educational Psychology 80 (3): 381-402. doi:10.1348/000709909x484479.

Way, N., R. Reddy, and J. Rhodes. 2007. "Students' Perceptions of School Climate During the Middle School Years: Associations with Trajectories of Psychological and Behavioral Adjustment." American Journal of Community Psychology 40 (3-4): 194-213. doi:10.1007/ s10464-007-9143-y. 
Weir, S., D. Errity, and L. McAvinue. 2015. "Factors Associated with Educational Disadvantage in Rural and Urban Areas." The Irish Journal of Education 40: 94-110. http://www.erc.ie/ documents/vol40chp6.pdf.

Young, J. F., L. Mufson, and M. Davies. 2006. "Efficacy of Interpersonal Psychotherapy-adolescent Skills Training: an Indicated Preventive Intervention for Depression." Journal of Child Psychology and Psychiatry 47: 1254-1262. doi:10.1111/j.1469-7610.2006.01667.x.

Zahorik, J., A. Molnar, K. Ehrle, and A. Halbach. 2012. "Smaller Classes, Better Teaching? Effective Teaching in Reduced-size Classes." Accessed March 30, 2018. http://epsl.asu.edu/ sage/documents/SAGE-0000-12-SRP.pdf.

Zullig, K. J., E. S. Huebner, and J. M. Patton. 2010. "Relationships among School Climate Domains and School Satisfaction." Psychology in the Schools 48 (2): 133-145. doi:10.1002/ pits.20532. 